\title{
A Logical Exploration of the Public Affairs Governance Ability of Chinese Local Government in the New Era
}

\author{
Ning Qiuhong ${ }^{1}$ \\ ${ }^{I}$ School of Public Administration, Party School of the CPC Central Committee, Ning Qiuhong, Taiyuan, Shanxi \\ 2293635069@qq.com
}

\begin{abstract}
Reviewing the development and innovation process of public management theory, the cooperative governance capacity of local government in public affairs has increasingly evolved into one of the important factors to measure the capacity of local government. Cultivating and enhancing the collaborative governance capacity of local government in public affairs is not only an important foothold for the capacity building of local government in the new era, but also an important foundation for us to realize good law and governance. It is not only necessary to adhere to and improve the social governance system based on joint contribution, joint governance and shared benefits, but also of great value to the modernization of China's national governance system and governance capacity. In such a valuable exploration, we for the new era of local government public affairs cooperative governance capacity construction research is necessary. The research of this paper is also based on this. On the basis of the current reality of local governance in our country, on the premise of adhering to the correct values, we should innovate a new government management system, transform government functions and improve the governance structure. Then innovatively put forward suitable for the current local government public affairs cooperative governance capacity construction optimization counter measures.
\end{abstract}

Keywords: local government, public affairs, cooperative governance, local government capacity

\section{THE INTRODUCTION}

At present, China is committed to promoting the modernization of national governance system and governance capacity in the great journey, in order to better respond to this great proposition of The Times. Enhancing government governance ability and innovating government governance mode become the key factors of government reform in China. In addition, with the advent of globalization, digitalization and information age, the diversity and complexity of public affairs are increasing day by day, and government governance is facing greater and greater challenges. As a new governance thinking in response to the needs of public governance, cooperative government has become the trend of public governance because of its innovation in solving public problems. Cooperation is not only an art in human social life, but also a social force. "In the eyes of the public, cooperation is a shop! But this little shop contained the whole world; it was a new and special order. As China enters the digital age, it is the logical choice and inevitable requirement to build a cooperative government to improve the governance ability and innovate the governance model.

\section{THE HISTORICAL BACKGROUND OF ADMINISTRATIVE CENTRALIZATION AND SOCIAL DECENTRALIZATION}

The dilemma between centralization and decentralization has been perplexing the optimization of power structure in China's national governance. At present, there have been a large number of studies on the relationship between the centralization power and local decentralization in China, such as the bottom line of decentralization between the central and local governments. On the other hand, there is also an increasingly obvious trend of diversification and decentralization in the development of local economy and society. From ancient China to the Republic of China, the centralized mode -- "centralized simple governance", although this mode is highly centralized, it is also highly simplified, and its penetration into the grass-roots society is relatively limited. After the founding of the People's Republic of China, it was transformed into the "omnipotent" control system mode. 
Administrative centralization has given birth to a series of "informal institutions" or "informal behaviors" in the local administrative system of our country. Therefore, a strange phenomenon appears in China's local administrative system: the coexistence, parallel and alternate use of formal system and informal system. This phenomenon has existed in ancient times and continues to this day. However, in the face of a variety of current public affairs governance, such as water conservancy, social relief, public health, education, pension services, etc., local governments cannot undertake alone, even if they undertake it, it is impossible to well implement this function. The good governance of local public affairs cannot be separated from the joint participation of enterprises, social organizations and the public. In our country, local entrepreneurs have also been assuming such a governance responsibility. Of course, this effort of local autonomy has never left the infiltration of administrative power, and it is also the local autonomous governance under the guidance of administrative power. The dual roles of local government officials, loyal to both the local and the national, are well established. Therefore, in China's local public affairs governance, administrative centralization and social decentralization are always intertwined. We have both the tradition of administrative centralization and the history of social decentralization, but different from the social development in Western Europe, China's social decentralization has never left the guidance and assistance of administrative centralization. Administrative centralization and social decentralization are like a pair of twin sisters, and they are born interdependent.

\section{THE INTEGRATION OF LOCAL GOVERNMENT COMMONNESS AND PERSONALITY GOVERNANCE}

In the grip and pull of the two relative forces of administrative centralization and social decentralization, local governments play two roles in the governance of public affairs. On the one hand, under the "pressure" system of centralization, local governments carry out the administrative instructions of their superiors regardless of the cost, showing the characteristics of "closely following"; On the other hand, as local managers and even as "indigenous people", local governments should consider the needs of local society and local citizens and "take care of local villagers" in a timely manner. Therefore, local governments sometimes encroach on local interests in the name of the state, and sometimes seek resources from the state in the name of the local. At present, local leaders fully carry out the functions required by superiors, while grass-roots civil servants care more about local public affairs, such as education development and environmental protection, than county and township leaders. The dual role of local government in the governance of public affairs is not only related to the cooperative governance of officials, but also related to the dual identity of gentry, another important subject of local governance. In local government governance, the tradition of cooperative governance between local government and social personages still exists in the governance process of some local governments. For example, in the case of Hangzhou, "social composite subjects" governing urban public affairs, the local government cooperated with enterprises, media, experts and the public in the composite governance, and some "public entrepreneurs" with public spirit emerged as leaders of various undertakings. Although this case is regarded by many scholars as an innovative case that local government absorbs foreign cooperative governance experience of government, market and society, this paper believes that these local governance reforms are to a large extent inherited the tradition of cooperative governance between local government and gentry since ancient times in China. Therefore, local governments will not only "follow closely" to implement the decisions of the central government, but also adhere to the common governance model of local governments. At the same time, in line with the intention of "benefiting the village", it will also assume the governance responsibility of public affairs in the area under its jurisdiction, and take individual requirements into account in the specific analysis of specific problems. Whether in the past or at present, this combination of commonness and individuality makes local governments choose and balance their interests between the state and the society, so as to make decisions that are more in line with the current governance context.

\section{COOPERATIVE GOVERNANCE -- THE NEW LOGIC OF PUBLIC AFFAIRS GOVERNANCE IN THE NEW ERA}

\subsection{What is cooperative governance}

Consult data knowable, cooperative management, it is the general term that crosses domain management form really. In this form, actors from different fields are committed to achieving common goals or providing public services through interconnection, integration of forces and coordination of relations. Actors in various fields often carry out cooperation in various forms, including government-enterprise cooperation, government-civil society cooperation, enterprise-civil society cooperation, and government-enterprise-civil society tripartite cooperation. It is not difficult to discover that the bright spot of cooperative management depends on "cooperation". And the word "cooperation" has completely different meanings in different contexts. Here, the "cooperation" in cooperative management is necessary and in the market "cooperation" make one distinction, so that understand the essentials of cooperative management truly. In the market 
environment, the cooperation between market subjects is usually for the utilitarian purpose, that is, in order to maximize the common profit, the two parties mainly cooperate by signing a contract, and the gains and losses brought by mutual cooperation can often be accurately calculated. The cooperation initiated by cooperative governance is considered as a social cooperation, which is based on specific value goals, namely, the realization of common goals and synergistic effects. The partners cooperate mainly based on communication and trust, and the ultimate realized value cannot be calculated. Finally, compared with the original public affairs governance logic, in a word, cooperative governance delivers the following new ideas. First, public interest orientation. The basic starting point of cooperative governance is to solve public problems and meet the needs of public services to achieve the maximum of public interests. Second, decentralization orientation. Cooperative governance has broken the traditional governance structure. The government no longer dominates governance. Instead, governance subjects outside the government field jointly govern public affairs and carry out joint actions through equal cooperation. Third, social and market orientation. From the perspective of "the relationship between government, society and market", cooperative governance advocates to increase the forces of market and society, reduce the existence of government, stimulate the vitality of market and society, let the market play a decisive role in economy, and let civil forces play a greater role in the social field. Of course, cooperative governance is not a brand new thinking. It still inherits some elements of governance, management and service logic, such as the use of coercive force as the last governance means, and always attaches importance to the role of the market, maintaining public order and realizing public interests.

\subsection{Characteristics of cooperative governance capability}

By the local government public affairs governance ability to define the concept of cooperation, we can find that the local government public affairs cooperation governance has the following characteristics: one is that the local government public affairs cooperation governance systemically, the local government public affairs cooperative governance is composed of each branch power system. Whether the cooperative governance ability of local government in public affairs can play its due role is closely related to the correlation mode between the abilities of each branch. The ability of each branch is not a simple causal and linear relationship, but a very complex correlation. If the abilities of each branch can coordinate with each other, complement each other fully, connect properly and match reasonably, the optimal overall effect can be produced and the maximization of positive functions can be realized. However, if each branch ability friction, mutual constraints, internal friction, will greatly reduce the comprehensive function of the branch ability, or even complete failure, resulting in the emergence of the overall negative function. Therefore, in order to give full play to the overall optimal function of the cooperative governance capacity of local government in public affairs, attention must be paid to the arrangement, combination and connection mode of each branch capacity. Second, the cooperative governance capacity of local governments in public affairs is dynamic. The cooperative governance ability of local government's public affairs is not a fixed ability, it will change accordingly with the change of time and space. The development of The Times and the changes of the economic and social public power of local government and local government controlled should be under the premise of the local governments play a key role in public affairs cooperation governance will arouse the enthusiasm of the civil society participation in public affairs governance, governance to non-state actors to become public affairs cooperation partners to create a good environment. This function transformation of local government not only releases space, provides energy and creates opportunities for the growth of civil society, but also helps to promote the non-government subject from the original passive manager to equal governance partner. Third, local government's public affairs cooperation ability is the way to realize the cooperation between government and civil society. Cooperative governance is the logical choice of public affairs governance mode with the rise of governance and good governance theory. In accordance with the concept of governance and good governance, we should advocate the governance of public affairs. The government and civil society should work together to jointly govern public affairs. The essential characteristic of governance is that it is the cooperative management between government and civil society, and good governance is a novel relationship between government and civil society, and it is the best state of both. It can be seen that the subject of governing public affairs is not only the government, but also non-governmental organizations, citizens and even enterprises. As long as they are recognized by the society, they can become the subject of governing public affairs. With the increase of governance subjects, the role and status of each subject in public affairs governance becomes the key factor whether governance can achieve the desired effect. Especially in cooperative governance, the handling of cooperative relationship becomes the focus of attention because there are many subjects involved, and the nature of each subject is different, and the goals, values and motivations of each subject are different. It can be seen that governance and good governance only advocate cooperative governance in the concept, but whether cooperative governance will happen or whether it will work well, these are the issues that need to be further solved. The cooperative governance ability of 
local government in public affairs is to promote the construction of cooperative relationship, the occurrence of cooperative behavior and ensure the generation of good cooperative performance through the efforts of the government. In short, the cooperative governance capacity of local government in public affairs builds a bridge for the cooperation between the government and civil society, and is a strategic approach to realize the cooperation between the government and civil society. The cooperative governance ability of local government in public affairs requires local government to make corresponding adjustments in culture, function and behavior to achieve the established goals.

\section{CONCLUSION}

Management is decision making, and only a good management mode can stimulate better social innovation potential. Therefore, the implementation of cooperative governance is a good way for the Chinese government to reform its own shortcomings and mobilize the active participation of the market, society and citizens under the background of promoting the modernization of governance capacity. It is a feasible choice to apply high technology and digital engineering to build a service-oriented government. It is a reasonable means to properly deal with the relationship between government, market and society, an effective tool to overcome market failure, government failure and voluntary failure, and an important form of democratic administration. It is an ideal model for pooling forces and integrating resources to implement major public projects and meet people's ever-growing demand for public services. With the development of The Times, economic, political, cultural, social and other fields are changing with each passing day, which has created a favorable development environment and provided favorable conditions for the realization of cooperative governance. For example, the development of market economy ensures a large amount of financial and material resources required for cooperative governance; the enhancement of civic awareness and the prosperity of social organizations; the richness and diversity of cooperative governance subjects; the continuous revision and improvement of legal systems; the guarantee that cooperative governance will have laws to follow and a basis for governance: The increasingly developed information and communication technology provides strong technical support for cooperative governance. And so on. It can be seen that cooperative governance, as the ideal logic of dealing with public affairs in China, has bright development prospects and unlimited development potential. Finally, focusing on the practice of the logic of cooperative governance in China, some local governments in China have set up typical examples of cooperative governance and achieved remarkable results. For example, Baoji's "comprehensive governance of the Weihe River", "new mode of digital urban management" and "network governance that breaks through the poverty alleviation and development strategy of the Xishan Mountains" are all practical templates of cooperative governance. They have improved local public services to the greatest extent and achieved ideal governance effects. Therefore, no matter from the perspective of its own advantages, objective conditions or practical effects, cooperative governance, as a new logic to deal with public affairs in China, is a wise and inevitable choice. Of course, this does not mean that cooperative governance is perfect. In its long practice process, it will inevitably encounter bottlenecks or produce a number of problems. In the process of implementing cooperative governance in China, it is just like "crossing the river by feeling the stones". While striving to achieve cooperative governance, we still need to constantly examine its applicability and sustainability in China.

Finally, the capacity building of cooperative governance of local government's public affairs is a grand systematic project. The construction of local government's public affairs cooperative governance capacity involves many factors such as government concept, government system, government mechanism, government functions, government tools, government personnel and so on. It is a complex system project. It is neither scientific nor realistic to hope that you will succeed in a single battle. Only through continuous consolidation of theoretical research, continuous summary of practical experience, follow the basic law of quantitative change to qualitative change, in order to finally achieve the expected goal.

\section{REFERENCES}

[1] David W. Johnson, The Tools of Government, A Guide to the New Governance, Oxford: Oxford University Press, 2002.

[2] F. Kettl, D., The Transformation of Governance. Baltimore: Johns Hopkins University Press, 2002.

[3] E. Sorensen, Metagovernance: the Changing Role of Politicians in Processes of Democratic governance, The American Review of Public Administration, 2006.

[4] K. Provan, B. Milward, Do Networks really work? A Framework for Evaluating Public-sector Organizational networks, Public Administration Review 2001.61 (4).

[5] J. Bendor, A.Glazer, T. Hammond, Theories of Delegation, Annual Review of Political Science 2001 .

[6] B. Kjaer, Applying "Design by Governance", Governance 25(10) (2004) 40-51.

[7] H. Barringer, Implementing Programs in 
Interorganizational, Networks International Journal of Public Administration, 2003.

[8] W. Maloney, G. Smith, G. Stoker, Urban Governance and Social Capital, Political Studies, 2000.

[9] G. Stoker, New localism, Progressive Politics and Democracy, Oxford: Political Quarterly/Blackwell, 2004.

[10] S. Goldsmith, W. Eggers, Governing by Network, Washington: Brookings Institution Press, 2001.

[11] M. Moore, Creating Public Value. Cambridge, MA: Harvard University Press, 1995.

[12] H. Bang, Governance as Social and Political Communication, Manchester: Manchester University Press, 2003.

[13] G. D. Penna, Managing in Network Settings, Policy Studies Review, Springer, Berlin, Heidelberg, 1999. 